\title{
An overview of research on romantic relationships. The case of negative emotions
} Andreea Ursu, Maria Nicoleta Turliuc 


\title{
An overview of research on romantic relationships. The case of negative emotions
}

\author{
Andreea Ursu ${ }^{a *}$, Maria Nicoleta Turliuc ${ }^{b^{*}}$ \\ ${ }^{a, b}$ Doctoral School of Faculty of Psychology and Education Sciences, "Alexandru Ioan Cuza" University of Iaşi, Toma Cozma Street 3, 700704, Iaşi, \\ Romania \\ *Corresponding author: ursu.anndreea@gmail.com
}

Abstract

Keywords: emotion, romantic relationships, soft, hard, fear-based, flat emotions
The universal human tendency to form close relationships, the basic needs satisfied by social relationships and the centrality of them to human existence were ones of the most important reasons why people started to research the concept of close relationships and its impact on the daily life.

In the last 4 decades, the studies of the interpersonal relationships have been one of the favorite areas in the social psychology. The several strong theories and highly generative research paradigms on interpersonal relationships are the result of researchers' interest in this concept. A central role was played by the romantic relationships concept. At the beginning of the 1980s, the publication of studies on relationship types began, and later on, articles on theories about factors of formation, development, maintenance and dissolution of one romantic relationship were published. Across time, they discover that social relationships represent the context in which people experience their most intense emotions, both positive and negative. Especially, the experience and expression of emotions are influencing the formation, maintenance and dissolution of close relationships. Thus, based on these assumptions, this paper is an overview of synthesizing (a) how the concept of romantic relationships is view by different theories; (b) what are the benefits of them; and (c) which type of negative emotions are experienced within a romantic relationship.
Schlüsselworte:

Erregung,

Romantische

Beziehungen,

Weich, Stark,

Angst-basierende

Flach Emotionen
Die universelle menschliche Tendenz, enge Beziehungen zu bilden, die grundlegenden durch sozialen Beziehungen erfüllten Bedürfnisse und die Zentralität von ihnen für die menschliche Existenz wurden diejenigen der wichtigsten Gründe gewesen, warum Menschen begonnen, das Konzept der engen Beziehungen und ihre Auswirkungen auf das tägliche Leben zu erforschen.

In den letzten 4 Jahrzehnten haben die Studien der zwischenmenschlichen Beziehungen zu einem der beliebtesten Bereiche in der Sozialpsychologie gewesen. Die mehreren starken Theorien und hoch generative Forschungsparadigmen auf die zwischenmenschlichen Beziehungen sind das Ergebnis der Forscher Interesse an diesem Konzept. Eine zentrale Rolle wurde von den romantischen Beziehungen Konzept gespielt. Zu Beginn der 1980er Jahre begann die Veröffentlichung von Studien über Beziehungstypen und später, wurdenArtikel auf Theorien über Faktoren der Bildung, Entwicklung, Wartung und Auflösung einer romantischen Beziehung veröffentlicht. Über die Zeit, entdecken sie, dass soziale Beziehungen den Kontext repräsentieren, in denen Menschen ihre intensivsten Emotionen erleben, sowohl positive als auch negative.Insbesondere beeinflussen die Erfahrung und Ausdruck von Emotionen, die Bildung, die Wartung und die Auflösung der engen Beziehungen. So auf der Grundlage dieser Annahmen ist dieses Papier ein Überblick über die Zusammenfassung über: (a) wie das Konzept der romantischen Beziehungen Blick durch verschiedene Theorien angesehen wird; (b) was die Vorteile von ihnensind; und (c) welche Art von negativen Emotionen in einer romantischen Beziehung erlebt werden.

\section{Introduction}

Forming a close relationship represent one of the fundamental social needs. By time, it has been proven that close relationships are influencing in a positive way relationship's outcomes. Due to their impact on mental and physical health, this concept is a central one for Social Psychology. Finkel, Simpson and Eastwick (2017) have reviewed the psychological literature on close relationships with the goal to extract its core principals. The 14 principles have been organized in 4 sets with topics related to (a) "What is a relationship?" (b) "How do relationships operate?" (c) "What tendencies do people bring to their relationships?" and (d) "How does the context affect relationships?". For the propose of this overview, we will present just the first set with its first 3 principles which are related to uniqueness, integration and trajectory of a relationship. In authors' opinion, the unique character of 
one close relationship is represented not only by the specific qualities of each partner, but also by the unique pattern resulted by the intersection of partners 'qualities. Thus, a relationship is more than a sum of its parts. This principle can be also analyzed from the statistical point of view. The Actor-Partner Interdependence Model applied to the dyadic relationships (Campbell \& Kashy, 2002) brought in attention the concept of relationship variance and the within variable type. In other words, a relationship is better understood if the dyadic context emerged by partners is also analyzed. Not only the uniqueness principle takes in account the mutual influence of partners, but also the integration principle, meaning that the boundaries between dyadic partners are weak, leading to the difficulty of discerning the measure in which one quality or one behavior is specific to one of partners; it is easier to see it as specific to the relationship. Another point that has to be presented is related to the trajectory principle. Literature of romantic stages suggests that the transition from the forming (the initial stage) to the short-term relationship (if the relationship does end) to the long-term relationship (if the short-term relationship does not end), and the partners desire to produce relationships-specific behavioral tendencies are the main characteristics of the trajectory principle.

Even though we presented the principles related to "What is a relationship?", we still consider important to present the definitions and characteristics of them in a trial of a better understanding of how this concept have been operationalized by different theories during time.

\subsection{Theories of romantic relationships}

In the late 1970s, Clark and Mills (1979) suggest that all social relationships are based on the principle of giving and receiving benefits between the persons involved. Taking this principle into account, the same authors suggest the existence of two types of interpersonal relationships communal relationships and exchange relationships. The main characteristic of communal relationship is that members feel the responsibility for the other's needs and welfare. Also, it is not necessary to keep tracking the needs or the benefits because the other will repay in a situation in which that benefit will be needed (Clark \& Mills, 1979; Clark, Mills, \& Powell, 1986). In other words, in communal relationships, the general norm is to express a general concern for the significant other or to give a benefit as a response to a need (Clark \& Mills, 1993). According to Clark, Mills and Powell (1986) the best examples for this type of interpersonal relationship are the friendships, romantic relationships and family relationships.

The concept of social relationships has been studied, also, based on the principle of interdependence between partners. Kelley and Thibaut (1978) suggest that the interdependence between two or more persons leads to the mutual influence at behavioral, attributional and perceptional level. Especially, Kelley et al suggest that if the behaviors, emotions and thoughts of two persons are mutually and causally interconnected, thus the persons are interdependent, and the relationship exists (Clark \& Reis, 1988). Berscheid and Ammazzalorso present that the majority of relationship researchers view the essence of a relationship as "the oscillating rhythm of influence that appers in the partners' interactions" (2001, p. 309). Therefore, if there is no interaction, there is no relationship, because during the interaction, persons involved in a communal relationship influence each other their behavior. Based on this principle, close relationships, especially wellestablished romantic relationships, are the most representative social relationships.

Attachment theory is another theory which has studied the concept of close relationships. In order to succeed it, Hazan and Shaver adapted the original theory developed by Bowlby (1988) to the relationships' specificity (1994). From this point of view, a close relationship is seen as the emotional bond developed with a significant other and maintained it during time with the goal of satisfying the basic needs of the partners. The emotional bond is represented by the experiencing and expressing the emotions which leads to the intimacy. From the point of view of intimacy theory (Reis \& Shaver, 1998; 1988), relationships create the framework of trust, stable acceptations and practices which lead the partners to disclosure the most intimate thoughts, feelings, events with the goal of feeling understood, cared for and validated.

In conclusion, persons in a romantic relationships feel responsibility for the significant other's needs and welfare, they feel no obligation to repay the benefit with a comparable benefit; they are mutually and causally interconnected, maintaining the relationship during time, because during their interactions they develop emotional bond and because they are understood, cared for and validated in their relationships, they will disclose personal thoughts, events, situations being aware that their needs will be satisfied. This is the idealistic situation, in which partners are committed to their relationships, in which 
partners perceived the benefits of their romantic relationship.

\section{The protective role of romantic relationships}

Forming a stable, romantic relationship is a basic human need and it produces positive emotions (Baumeister \& Leary, 1995); it provides a social identity, it is a source of social integration during the emerging adulthood and it contributes to a positive self-conception (Meier \& Allen, 2008); it satisfies the need for security (Hazan \& Shaver, 1994); it protects partners from social isolation; it is a source of emotional and physical support; it has an influence on biological processes (Kiecolt-Glaser \& Newton, 2001) and is it one of the most important element of the recovery of environment in case of a trauma (Johnson \& Williams-Keeler, 1998). Other positive impacts to the individuals' lives are related to companionship, friendship, love, security, and happiness (Markey, Markey \& Gray, 2007). In addition, married people live longer, are less likely to engage in risky behaviours, recover more quickly from mental and physical illnesses (Coombs, 1991).

In this part of our overview, we will present the impact of romantic relationships on mental and physical health of partners by taking in account variables as gender and marital status. Also, we will present the mechanisms (selection, social support, behavioral regulation and belongingness hypothesis) which influence the link between romantic relationships and mental and physical health.

\subsection{Romantic relationships' benefits}

Some preliminary work related to the benefits of romantic relationships on well-being was carried out in the early 1990s by Coombs (1991) who presented in his literature review the link between marital status and several wellbeing' indices as: alcoholism, suicide, morbidity and mortality, schizophrenia, other psychiatric problems, and self-reports of happiness. As he was predicting, the conclusions of the study suggested that high rates of alcoholism, suicide, mortality and morbidity, schizophrenia, others psychiatric problems (mental hospital admissions; mental disorders) and low rates of self-reported happiness are more likely to occur within unmarried individuals, especially men. Besides this, unmarried individuals experience also more stress and emotional pathology than the married ones.
A well-known aspect studied in the context of romantic relationship and well-being link is represented by gender. Although, its impact on romantic relationships has been intensely studied during the last 3 decades and the results are suggesting that interpersonal relationships have a more positive impact on men' health than on women' health (Coombs, 1991), Markey, Markey and Fishman Gray (2007) suggested that these results should be interpreted with caution because the way in which women and men are affected by their relationships in specific health area still has to be explored. In their study, they address the question of gender and individuals' perception of their romantic partners' influences on their health. Their results suggest that both genders tended to perceive their partner as having more positive than negative influences on their health; contrary to the literature, women, more than men, tended to perceive more positive influences on their health caused by their partner; more precisely, women tended to think that their partner have an influence on health's domains as physical activities and self-esteem, while, both genders tended to think that their partner has positive influences in domains as healthy eating habits, seeking medical help, developing traits/ characteristics which enhanced their sense of health and wellbeing. Also, Simon and Barret (2010) suggest that being in a romantic relationship has more positive impact on women' mental health than on men 'mental health.

On account of the assumptions presented upper we can say that the gender roles are in a continuous change and men are influencing positively the woman's health with whom they are in a relationship, in an intent to reduce the persistence of gender inequality in interpersonal relationships.

Recently, several attempts started to be made in order to address another important aspect in the studying of romantic relationships and health link, namely the benefits' differences between people involved in commitment nonmarital relationships and single (Braithwaite, Delevi, \& Fincham, 2010), and marital and non-marital relationships (Uecker, 2012). These authors make reference to the benefits related to physical, mental health and well-being. Comparing with other times, curent women and men are involved in more non-marital relationships. The age when people are getting married is increasing, non-marital sex and cohabitating with the partner are more accepted by the society, partners' focus on developmental of social and job necessary skills for work, non-traditional attitude toward 
marriages and the need of them, all of these lead to the increasing of involvement in non-marital relationships. To address this aspect (to cover this gap) research has been conducted it and it has been shown that individuals involved in non-marital commitment relationships experience less mental health problems, more precisely, fewer depressive symptoms, than those not involved in relationships (Simon \& Barrett, 2010), were less likely to be overweight and they have less problematic behaviors because of the reduced number of sexual partners which leads to a reduction of involvement in risky behaviors (Braithwaite, Delevi, \& Fincham, 2010). Not only the nonmarital romantic relationships versus singles has been study but also marital versus non-marital ones. Recent research suggests that people involved in one romantic relationship and not cohabiting have lower level of psychological distress than the married ones; people involved in one relationship (cohabiting or not) and married people may have less drinking habits; married young adults and those involved in a non-marital relationship and living together have the higher level of satisfaction (Uecker, 2012). In other words, forming any type of romantic relationship has a positive impact on mental or/ and physical health of partners. Still, these results should be interpreted with caution. Coombs (1991) in his review concluded that being involved in unhappy relationships can have a negative impact on partners' health by creating high level of psychiatric distress, development of mental illness. As well, Markey, Markey and Fishman Gray (2007) have gone as far as to assert that both, women and men who perceived positive impact on their health because of their partners, tended to be involved in more communal relationships.

\subsection{Mechanisms of romantic relationships}

Research on the protective impact of marriage suggests that selection, social support, behavioral regulation and belongingness are the mechanisms that might influence the relation between marriage and well-being. Firstly, the selection hypothesis suggests that there is a greater possibility for individual with a better physical and mental health to get married and to remain married (Braithwaite, Delevi, \& Fincham, 2010; Uecker, 2012)), because they are least likely to die (Lillard \& Waite, 1995) and that emotionally mature people are more likely to get married, to be happy and to live healthier (Coombs, 1991). Secondly, the social support hypothesis suggests that one of the benefits of romantic relationships is that provides to persons emotional satisfaction and protect them against daily life stressors (Braithwaite, Delevi, \& Fincham, 2010), within romantic relationships, people find companionship with a spouse who provides emotional gratification (Coombs, 1991). Thirdly, the behavioral regulation hypothesis suggests that people involved in one marriage are less likely to assume and be involved in risky behaviors (Braithwaite, 2010). Finally, the belongingness hypothesis suggests that the need to form and maintain significant interpersonal relationships is a fundamental human motivation and by studying this, it can be understood better the human interpersonal behavior (Baumeister \& Leary, 1995).

In conclusion, taken together, these findings suggest that the link between romantic relationships and its benefits on mental and physical health of partners still has to be studied due to of its complexity which it is greater than what it was predicted by literature.

\section{Emotions and romantic relationships}

A great deal of work has been done showing the associations between emotions and romantic relationships. Literature suggests that in the context of romantic relationships, people experience the most intense emotions, both negative and positive (Fitness \& Fletcher, 1990) because of the partners' highly interconnected behavior (Berscheid \& Ammazzalorso, 2001), which leads to the idea that emotions are not context free as it has been suggested across time (Fitness \& Fletcher, 1993).

In the following section of this overview we will present the specificity of emotions in the context of romantic relationships; a categorization which divides them in soft, hard, flat and fear-based emotions, and in emotions caused by the events within or outside of relationships; in which situations the negative emotions have a positive impact on the romantic relationships and which negative emotions are felt within a couple (hurt, anger, disinterest, boredom).

Emotion, in the context of a romantic relationship, is seen as the leading element, which "organizes key responses to intimate others, acts as an internal compass focusing people on their primary needs and goals, and primes key schemas about the nature of self and other" (Jonhson, Makinen, \& Millikin, 2001, p. 147). Furthermore, because emotions have a central role in developing and maintaining of romantic relationships, studying them within a couple leads to better understanding of emotional experience in intimate relationships (Schoebi 
\& Randall, 2015). It is worth noting that some researchers suggest that when people refer to emotion in couples, they are talking about the emotions which have a high level of arousal, defining them using physiological characteristics as knees tremble, flushed faces, hearth pound (Berscheid \& Ammazzalorso, 2001).

\subsection{Categorization of emotions}

Early evidence suggest that most studies have been focused on the emotions' valence, positive and negative (Berscheid \& Ammazzalorso, 2001) without taking into account other types of categorization. But this gap started to becoveredin the last few years, with researchers' focus on this topic. For example, Integrative Behavioral Couple Therapy (IBCT) and Emotionally Focused Couple Therapy (EFT) focused more on negative emotions felt within couples, because the early literature has emphasized the important role of negative emotions in couples (Johnson, 2008). IBCT (Dimidjian, Martell, \& Christensen, 2008; Christensen, Jacobson, \& Babcock, 1995) have categorized negative emotions felt within romantic relationships in soft and hard. Moreover, Sanford and Rowatt (2004) have suggested the existence of fear-based emotions and Sanford (2007) has suggested another type of negative emotion, the flat emotions.

Buck (1999) has proposed to replace the positivenegative distinction with selfish-pro-social one. He has suggested that selfish emotions are the negative ones, associated with the right hemisphere and with amygdala and they are related to the self-preservation, competition, conflict and fighting, while the pro-social ones have a positive valence, associated with the left hemisphere and are related to the maintain of interpersonal relationships, focused on attachment and cooperation. Buck's approach of emotions could have been the base for the categorization of negative emotions in soft and hard made by IBCT. Hard emotions are selfish emotions include anger and close emotions to anger, associated with the assertion of power and control in one relationship, whilst soft emotions are the pro-social ones, including sadness, hurt and other negative emotions associated with the vulnerability experienced and expressed in one's relationship. Besides this, fear-based emotions are a mixture between soft and hard emotions. For example, anxiety, a fear-based emotion, is similar to the soft emotions because is suggesting a degree of vulnerability and weakness but is it similar also to hard emotions because it involves a high level of tension and arousal. As opposed to hard and soft emotions, flat emotions are negative emotions, which include emotions as apathy, boredom, disinterest characterized by a low level of arousal and withdrawal from conflict (Sanford, 2007).

Based on the assumption that hard, soft and fear-based emotions have different impact on romantic relationships outcome as dyadic satisfaction and even the literature suggests that they share the same variance because all of them are placed in the negative emotions category, Sanford and Rowatt (2004) tested this issue and they found that soft emotions predicted positive functioning (high satisfaction, low conflict, and low avoidance) whereas hard emotions predicted negative functioning (low satisfaction, high conflict, and high avoidance) and fear-based emotions were associated with poor relationship functioning, predicting relationship anxiety. In other study, Sanford (2007) suggest that increases in hard emotions lead to increases in negative communication and decreasing in positive communication and they are associated with detrimental changes in the behaviour of both partners. By way of contrast, soft emotions have a less detrimental impact on partners' behaviour and increases in soft emotions were associated with increases in their positive communication style and decreases in their partner's negative communication style which leads to the conflict resolution.

It has been suggested that hard emotions are not negative for a relationship all the time and soft emotions do not have a positive impact in all the situations and this seems to be a reliable approach for studying the impact of these types of emotions on romantic relationships. Literature suggests that emotions can be multifaceted, and it can have both positive and negative impact for a relationship. For example, Sanford (2007) mentions that in a situation of partners' withdrawn or continually conflict, increasing conflict can have a positive impact, helping to solve the conflict, leading to positive changes for meeting the partners' needs. In comparison with hard emotions, soft emotions have a negative impact when they are chronic or extreme. Kashdan (2006) indicates that partners which listen everyday soft emotions which require responsiveness, provision of reassurance and comfort will feel fatigue, burnout and negative mood contagion. Moreover, McNulty (2010) suggests in his review that the majority of interventions for treating marital distress are tending to use thoughts and behaviours associated with positive emotions, but these positive processes tend to have results in the case of relatively healthy couple, while for 
couples with severe problems, the more-negative processes tend to be more efficiently.

In conclusion, taken these together, the relationship between soft, hard and romantic relationships is more complex than it has been predicted and the results related to the beneficial impact of soft emotions or the negative impact of hard emotions should be interpreted with caution. Related to flat emotions, we found the absence of the research surprising on this topic in the light of their importance in the dissolution of romantic relationships. Tsapelas, Aron, \& Orbuch (2009) suggest that not just conflict has a negative impact on relationships, but also boredom, seen as the lack of excitement, it seems to shape relationships over time and to predict less satisfaction and Sanford (2007) suggested that flat emotions are associated with detrimental types of communication and men tend to report more flat emotions than women. Literature presents that flat emotions have a negative impact on relationships, in the context of a severe conflict, but they can be perceived as appropriate in the context of a mild one.

\section{Conclusions}

This overview adds to a growing body of literature findings related to how was operationalized the concept of romantic relationships by different theories; benefits of them; and which type of negative emotions are felt within a romantic relationship.

In the first part of our research, we underlined the most important theories related to the concept of romantic relationships. Across time, the romantic relationships have been seen as (a) communal relationships, in which people feel the responsibility for expressing concern for the other one and for his/her welfare, satisfying the significant other's needs, but they do not feel an obligation for repaying the benefits; (b) an interdependency between partners, their behaviors, emotions and thoughts being mutually and causally interconnected and their interactions are the proof that the relationship exists; (c) an emotional bond developed with a significant other and its maintenance is satisfying the basic needs during time; (d) the disclosure of sensible and vulnerable events in a context in which the person which disclosures, will feel understood, cared for and validated. As we can see, satisfying the needs of a significant other, in a context of mutually and causally interconnection and disclosure the sensible events to a person in which they will find trust and understanding are the main characteristics of a romantic relationship.
In the second part, we presented the benefits of romantic relationships on partners' wellbeing, physical and mental health. Although, early literature suggests that the positive impact of romantic relationships is greater for men, recent research suggests that both, men and women report more positive influences than negative, but they report different domains of health in which they felt the influences. Another important variable which has been studied in this context is represented by the marital status and it has been suggested that forming any type of romantic relationship has positive impact on personal outcomes, namely, people involved in one romantic relationship and not living together have the lower psychological distress; married people and people involved in one committed relationship have the less drinking habits and, moreover, the higher level of satisfaction has been found at married and at those involved in a non-marital relationship and living together. Regarding the distinction between single/ involved in a committed relationship, we can say that those involved in a committed relationship have fewer depressive problems. Despite of the evidence for the benefits and the protective role of romantic relationships on personal outcomes as wellbeing, physical and mental health, we have to interpret these results with caution because people which report a positive impact of their relationship have at least a medium level of dyadic satisfaction. Also, there are studies which report a negative impact of relationship when people are unhappy and unsatisfied.

In the last part of this paper, we presented how are emotions analyzed in the context of romantic relationships, some new typologies and types of emotions, their impact, and a focus on four negative and destructive emotions which can be sometime felt within a couple. There are therapies which have been seen the emotion as an important element for restabling the emotional bond which have been felt at the beginning of the relationship. Soft emotions are emotions which help the restabling of the emotional bond while hard, flat and fear-based emotions have a negative impact. Even, there are studies which suggest the positive impact of soft on relationship functionality, we have to interpret these results with caution because not all the time a soft emotion will have a positive impact and a hard or flat emotion will have a negative impact. Emotions, in the context of romantic relationships are multifaceted and their impact depends on the context also.

The majority of research which has been studied emotions in the context of romantic relationships has used 
a quantitative approach. We recommend, for future studies, a qualitative approach for a better understanding of their effects on romantic relationships. Also, emotions, more specifically, the negative soft, hard, fear-based and flat emotions, have been studied in transversal studies. Although relevant, this kind of research does not offer sufficiently information about the impact of emotions on relationship's outcomes. To cover this gap, we think that is it important to assess the impact of emotion and the impact of its related processes (recognition, expression, regulation) using repeated measures or longitudinal approach. Moreover, because of the interdependency between partners, it would be interesting to assess how partners influence their emotions and how the influence is felt on the dyadic satisfaction using a dyadic approach for interpreting the data.

In summary, emotions are an important aspect in the landscape of romantic relationships and emotions can shape the link between relationships and health outcomes.

\section{Acknowledgments}

This article was presented at The Fifth International Conference on Adult Education, 2018, Iaşi, Romania.

\section{Authors note:}

Ursu Andreea - Ph.D. student, Doctoral School of Faculty of Psychology and Education Sciences, "Alexandru Ioan Cuza", University of Iaşi, Romania.

Turliuc Maria-Nicoleta - Professor, Ph.D., Psychology Department, Faculty of Psychology and Education Sciences, "Alexandru Ioan Cuza", University of Iaşi, Romania.

\section{References}

Baumeister, R. F., \& Leary, M. R. (1995). The need to belong: desire for interpersonal attachments as a fundamental human motivation. Psychological Bulletin, 497-529.

Berscheid, E., \& Ammazzalorso, H. (2001). Emotional experience in close relationships. In G. J. Fletcher, \& M. S. Clark, Blackwell Handbook of Social Psychology:

Interpersonal processes, pp. 308-330. Malden, MA: Blackwell Publishers Ltd.

Braithwaite, S. R., Delevi, R., \& Fincham, F. D. (2010). Romantic relationships and the physical and mental health of college students. Personal Relationships, 17, 1-12.

Buck, R. (1999). The biological affect: a typology. Psychological Review 106 (2), 301-336.
Campbell, L., \& Kashy, D. A. (2002). Estimating actor, partner, and interaction effects for dyadic data using PROC MIXED and HLM: A user-friendly guide. Personal Relationships, $327-$ 342.

Christensen, A., Jacobson, N. S., \& Babcock, J. C. (1995). Integrative Behavioral Couple Therapy. In N.S. Jacobson, \& A.S. Gurman, Clinical Handbook of Couple Therapy, pp. 3164. New York: Guilford Publication, Inc.

Coombs, R.H. (1991). Marital status and personal well-being: a literature review. Family Relations, 97-102.

Dimidjian, S., Martell, C.R., \& Christensen, A. (2008). Integrative Behavioral Couple Therapy. In A.S. Gurman, Clinical Handbook of Couple Therapy, pp. 73-106. New York: Guilford Publications, Inc.

Finkel, E.J., Simpson, J.A., \& Eastwick, P.W. (2017). The psychology of close relationships: fourteen core principles. The Annual Review of Psychology, Vol. 68: 383-411.

Fitness, J., \& Fletcher, G.J. (1993). Love, hate, anger and jealousy in close relationships: a prototype and cognitive appraisal analysis. Journal of Personality and Social Psychology 65 (5), 942-958.

Fitness, J., \& Fletcher, J. (1990). Emotion labelling in close relationships. New Zealand Journal of Psychology, 19, 63-69.

Hazan, C., \& Shaver, P.R. (1994). Attachment as an organizational framework for research on close relationships. Psychological Inquiry, 5(1), 1-22.

Johnson, S.M. (2008). Emotionally Focused Couple Therapy. In A.S. Gurman, Clinical Handbook of Couple Therapy, pp. 107137. New York: Guilford Publications, Inc.

Johnson, S.M., \& Williams-Keeler, L. (1998). Creating healing relationships for couples dealing with trauma: the use of Emotionally Focused Marital Therapy. Journal of Marital and Family Therapy, 24 (1), 25-40.

Jonhson, S.M., Makinen, J.A., \& Millikin, J.W. (2001). Attachment injuries in couple relationships: a new perspective on impasses in couple therapy. Journal of Marital and Family Therapy, 27 (2), 145-155.

Kashdan, T.E. (2006). Social anxiety and romantic relationships: The costs and benefits of negative emotion expression are context-dependent. Journal of Anxiety Disorders, 1-19.

Kiecolt-Glaser, J.K., \& Newton, T.L. (2001). Marriage and health: his and hers. Psychological Bulletin, 472-503.

Lillard, L.A., \& Waite, L.J. (1995). Till death will do us part: marital disruption and mortality. American Journal of Sociology, 100(5), 1131-1156.

Markey, C.N., Markey, P.M., \& Fishman Gray, H. (2007). Romantic relationships and health: An Examination of Individuals' Perceptions of their Romantic Partners' Influences on their Health. Sex Roles, 57, 435-445.

McNulty, J.K. (2010). When positive processes hurt relationships. Current directions in psychological science 19 (3), 167-171. 
Meier, A., \& Allen, G. (2008). Intimate relationship development during the transition to adulthood: differences by social class. New Dir Child Adolesc Dev., 119, 25-29.

Sanford, K. (2007). Hard and soft emotion during conflict: investigationg married couples and other relationships. Personal Relationships, 14, 65-90.

Sanford, K. (2007). The couples emotion rating form: Psychometric properties and theoretical associations. Psychological Assessment, 19 (4), 411-421.

Sanford, K., \& Rowatt, W.C. (2004). When is negative emotion positive for relationships? An investigation of married couples and roommates. Personal Relationships, 11, 329-354.
Schoebi, D., \& Randall, A.H. (2015). Emotional dynamics in intimate relationships. Emotion Review, 7 (4), 342-348.

Simon, R.W., \& Barrett, A.E. (2010). Nonmarital Romantic Relationships and Mental Health in Early Adulthood: Does the Association Differ for Women and Men? Journal of Health and Social Behavior, 51(2), 168-182.

Tsapelas, I., Aron, A., \& Orbuch, T. (2009). Marital boredom now predicts less satisfaction 9 years later. Psychological science, 20 (5), 543-545.

Uecker, J.E. (2012). Marriage and mental health among young adults. Journal of Health and Social Behavior, 53(1), 67-83. 